\title{
Different Trends of Distinct Time Points of AIDS Events Following HIV Diagnosis in Various At-risk Populations: A Retrospective Nationwide Cohort Study in Taiwan
}

\author{
Chun-Yuan Lee $\cdot$ Pei-Hua Wu $\cdot$ Po-Liang Lu $\cdot$ Fu-Wen Liang (D
}

Received: May 11, 2021 / Accepted: June 28, 2021 / Published online: July 10, 2021

(c) The Author(s) 2021

\begin{abstract}
Introduction: Acquired immune deficiency syndrome (AIDS) events at distinct time points after human immunodeficiency virus (HIV) diagnosis require various AIDS prevention strategies. However, no nationwide epidemiological surveillance studies have been conducted to explore the trends of distinct AIDS event time points in various at-risk populations. The aim of this study was to explore the issues
\end{abstract}

C.-Y. Lee

Department of Internal Medicine, Kaohsiung Municipal Siaogang Hospital, No. 482, Shanming

Rd., Xiaogang Dist., Kaohsiung City, Taiwan

C.-Y. Lee

Graduate Institute of Medicine, Kaohsiung Medical University, Kaohsiung, Taiwan

C.-Y. Lee · P.-L. Lu

Department of Medicine, College of Medicine,

Kaohsiung Medical University, Kaohsiung, Taiwan

C.-Y. Lee

e-mail: leecy8801131@gmail.com

P.-H. Wu · P.-L. Lu

Division of Infectious Diseases, Department of Internal Medicine, Kaohsiung Medical University Hospital, No. 100, Ziyou 1st Rd., Sanmin Dist., Kaohsiung City, Taiwan

P.-H. Wu · F.-W. Liang

Department of Public Health, College of Health

Science, Kaohsiung Medical University, No. 100,

Tzyou 1st Road, Kaohsiung City 807, Taiwan and characterize the determinants of AIDS status after HIV diagnosis.

Methods: This nationwide cohort study enrolled HIV-positive Taiwanese during 1984-2016. AIDS events were classified into three time points $(\leq 3,4-12,>12$ months) by their occurrence time after HIV diagnosis. The periods of HIV/AIDS diagnosis were divided into six categories according to the calendar year of HIV/ AIDS diagnosis: 1984-1991, 1992-1996,

\section{P.-H. Wu}

e-mail: hua830820@gmail.com

P.-L. Lu

Center for Liquid Biopsy and Cohort Research, Kaohsiung Medical University, Kaohsiung, Taiwan

\section{P.-L. Lu}

College of Medicine, Kaohsiung Medical University Hospital, No. 100, Ziyou 1st Rd., Sanmin Dist., Kaohsiung City, Taiwan

e-mail: d830166@gmail.com

F.-W. Liang ( $\square)$

Department of Medical Research, Kaohsiung Medical University Hospital, No. 100, Tzyou 1st Road, Kaohsiung City 807, Taiwan e-mail: fwliang@kmu.edu.tw 
1997-2001, 2002-2006, 2007-2011, and 2012-2016. HIV-positive Taiwanese during 1984-2011 were then selected to determine the factors associated with four AIDS statuses within 5 years after HIV diagnosis (no AIDS, AIDS $\leq 3$ months, within 4-12 months, $>$ 12 months) using multinomial logistic regression.

Results: Of 33,142 cases, we identified 15,254 (46\%) AIDS events. The overall AIDS incidence (events/100 person-years) peaked during 1992-1996 (20.61), then declined, and finally stabilized from 2002 (8.96-9.82). The evolution of the proportion of distinct time points of AIDS events following HIV diagnosis changed significantly in heterosexuals and intravenous drug users (IDUs) during 1984-2016 (decline at $\leq 3$ months in IDUs, decline at 4-12 months in IDUs, and increase at $>12$ months in heterosexuals and IDUs) but not among men who have sex with men (MSM). Time points at $\leq 3$ months remained at $>50 \%$ among MSM and at $>55 \%$ among heterosexuals. In multinomial logistic regression, IDUs (vs. men who have sex with men; MSM) had a lower risk of all AIDS statuses; heterosexuals (vs. MSM) had a higher risk of AIDS events $\leq 3$ months after HIV diagnosis.

Conclusion: The magnitude of AIDS in Taiwan has been stable since 2002. Enhancing early diagnosis among people with sexual contact and optimizing the HIV care continuum among heterosexuals and IDUs should be priorities for further AIDS prevention strategies.

Keywords: Acquired immunodeficiency syndrome; Drug users; Human immunodeficiency virus; Time point

\section{Key Summary Points}

AIDS events at distinct time points after HIV diagnosis require various AIDS prevention strategies; however, the trends of distinct AIDS event time points remain unknown.
This retrospective nationwide cohort study aimed to explore the trends of distinct AIDS event time points in various at-risk populations in Taiwan from 1984 to 2016.

The overall AIDS incidence in Taiwan has been stable since 2002. The proportion of AIDS event time points at $>12$ months after HIV diagnosis increased in heterosexuals and IDUs, and the proportion of AIDS time points at $\leq 3$ months after HIV diagnosis remained at $>50 \%$ among MSM and at $>55 \%$ among heterosexuals over the past 3 decades.

Enhancing early diagnosis among people with sexual contact and optimizing the HIV care continuum among heterosexuals and IDUs should be priorities for further AIDS prevention strategies.

\section{INTRODUCTION}

Acquired immune deficiency syndrome (AIDS) is a chronic, potentially life-threatening, immunocompromised status caused by human immunodeficiency virus (HIV) [1]. In addition to morbidity and mortality [2-7], AIDS events are associated with negative outcomes, such as relatively high rates of HIV transmission to sexual partners $[8,9]$, relatively high rates of treatment failure after combination antiretroviral therapy (cART) [10], a poor immunological response to cART [11], and possible neurological sequelae [12]. Therefore, surveying the trends of AIDS incidence in persons with HIV (PWH) and characterizing the determinants of AIDS events are essential to HIV care.

Since the introduction of cART [13-15], establishment of prophylactic therapy for opportunistic infections [16], programs promoting early initiation of cART [17], and improvements to the HIV care continuum [18], the incidence of AIDS has drastically declined [19]. Nevertheless, AIDS remains a threat to PWH worldwide [13, 20-23]. In Taiwan, several programs have been implemented to improve 
the HIV care continuum, such as free cART and anonymous voluntary counseling and testing (aVCT) for HIV among bisexual and homosexual people since 1997, screening of military recruits since 2000, and of prisoners since 2001, harm-reduction programs among intravenous drug users (IDUs) since 2005, an HIV case management program since 2007, and homebased and self-testing kits since 2016 [24]. However, our previous nationwide cohort study conducted in Taiwan for the period 1998-2012 indicated no decrease in the 2-year cumulative incidence of AIDS events over time. Approximately $30 \%$ of PWH had AIDS events within 2 years of HIV diagnosis, with nearly threequarters of AIDS events being observed at HIV diagnosis [25]. Therefore, further interventions to reduce the AIDS epidemic in Taiwan are imperative. However, our study was limited by a short observation period for each newly diagnosed PWH (2 years of follow-up after HIV diagnosis). With the prolonged survival of patients with newly diagnosed HIV infection under optimal care [26], it is important to explore the incidence of AIDS events beyond 2 years after HIV diagnosis to be able to implement relevant interventions.

Another unmet need is to survey the evolving proportion of AIDS events at distinct time points after HIV diagnosis, which requires various AIDS-prevention strategies. The occurrence of AIDS at HIV diagnosis indicates a late presentation of HIV $[5,27,28]$, whereas that after HIV diagnosis can be attributed to other issues, such as inadequate prophylactic therapy for opportunistic infections [29], late initiation of cART [30], changes in the timing of cART initiation [31-33], and poor adherence to cART $[34,35]$. Therefore, understanding the different characteristics associated with AIDS at or after HIV diagnosis may help to reduce the AIDS epidemic [25]. Moreover, the trends of observed AIDS events at diagnosis and during 2 years of follow-up among newly diagnosed HIV-infected Taiwanese people have also been shown to differ among various at-risk populations [25], which implies that AIDS prevention strategies should also be tailored to the evolution of distinct AIDS event time points in various at-risk populations. However, no nationwide epidemiological surveillance study has been conducted to explore the trends of distinct AIDS event time points in various at-risk populations in the past 3 decades.

Accordingly, we conducted this retrospective nationwide cohort study to fill this research gap. We used a nationwide HIV/AIDS database first to understand the dynamics of AIDS incidence after HIV diagnosis, then characterized the trends of AIDS incidence and evolving proportion of distinct AIDS event time points in various at-risk populations during 1984-2016, and finally determined the factors influencing AIDS status within 5 years of HIV diagnosis.

\section{METHODS}

\section{Data Source}

All data provided by the Health and Welfare Data Science Center were retrieved from the HIV/AIDS database of the Taiwan Centers for Disease Control (CDC)-operated Notifiable Diseases Surveillance System (NDSS), a national web-based platform for reporting several communicable diseases as required by law [25]. Both HIV infection and AIDS have been classified as notifiable diseases by law in Taiwan since 1984 . Healthcare providers are required to report patients' information (identification number, sex, date of birth, date of HIV/AIDS diagnosis, date of death, occupation, specimen source, route of HIV infection, HIV diagnosis region, and marital status) within $24 \mathrm{~h}$ of detection of HIV/AIDS. AIDS reporting is based on the CDC's revised 1993 AIDS case definition [36], and an AIDS event is recorded in the database only once per patient. The status [survival, death, or departure (meaning left Taiwan)] of each case is maintained by public health personnel.

\section{Study Design and Setting}

This study was a retrospective, nationwide cohort study covering the period from January 1984 to December 2016. It was approved by the Institutional Review Board of Kaohsiung Medical University Hospital (KMUHIRB-E (II)- 


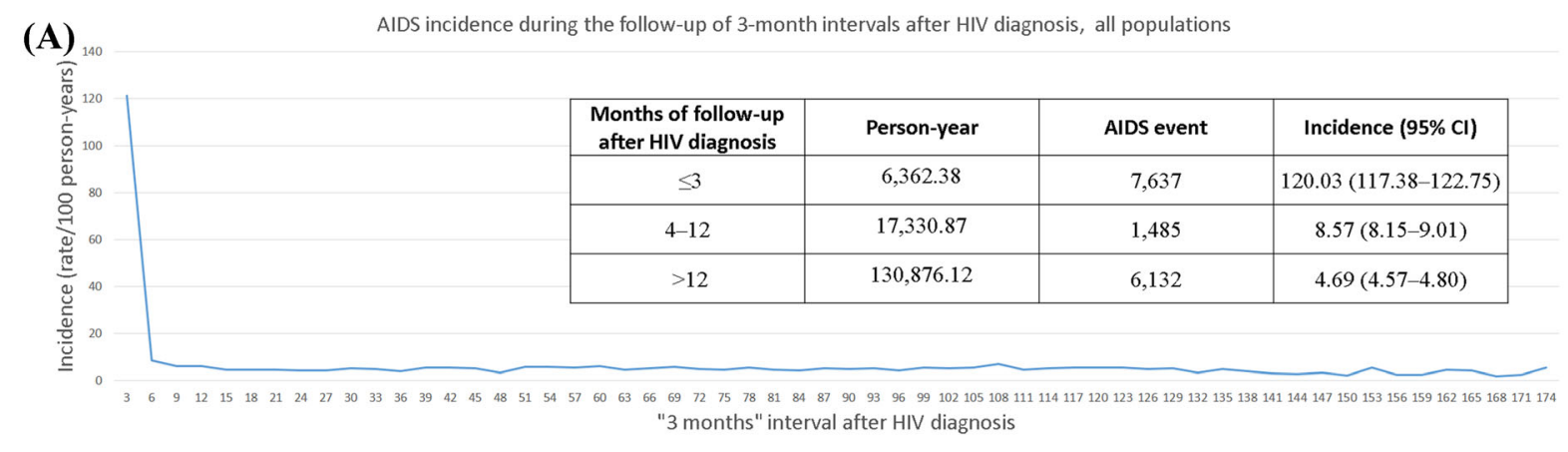

(B) ${ }_{300} \quad$ AIDS incidence during the annual year of follow-up after HIV diagnosis in each at-risk population

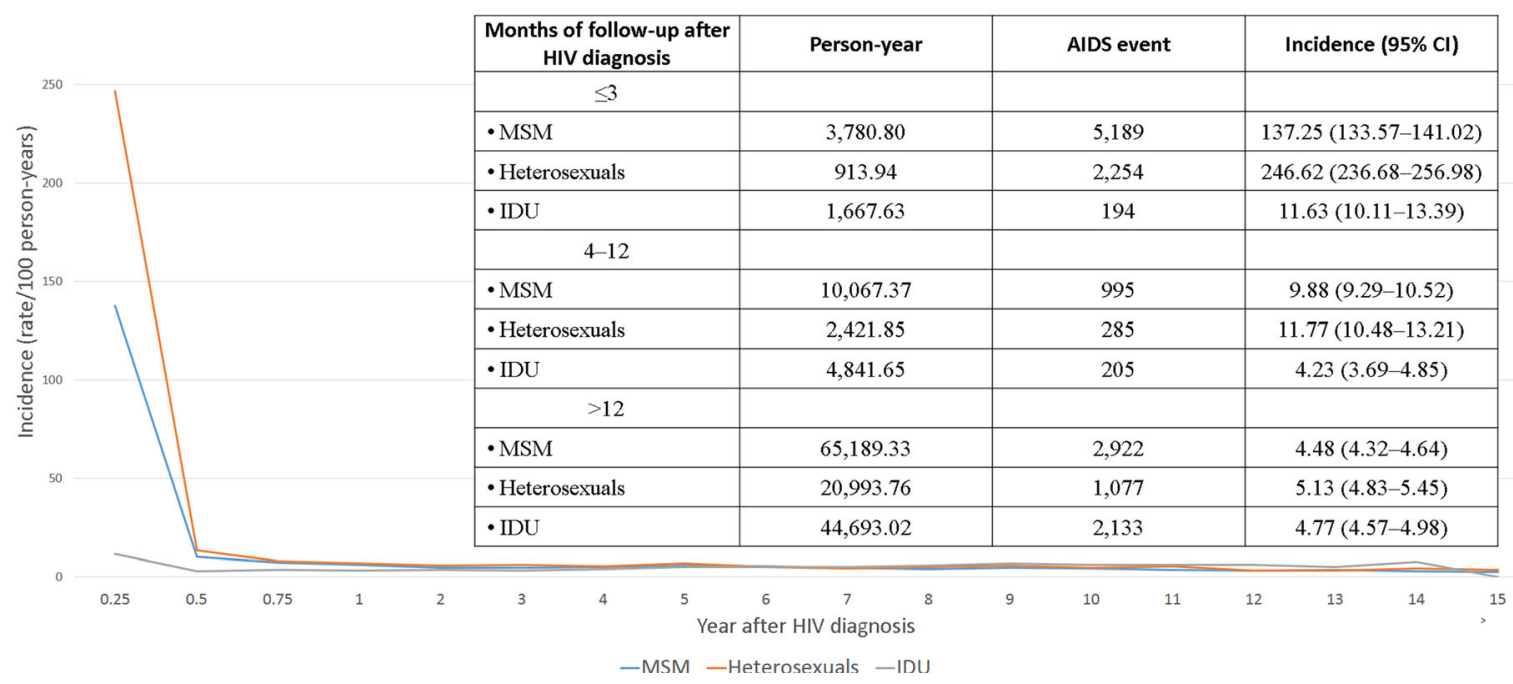

Fig. 1 Dynamics of AIDS incidence during the follow-up of 3-month intervals after HIV diagnosis in all populations (A) and the yearly follow-up after HIV diagnosis in each at-risk population (B). The AIDS incidence was 120.03 events/100 person-years (95\% CI 117.38-122.75) within 3 months; this rapidly declined to 8.57 (95\% CI

20200084), who waived the requirement for informed consent. The study was carried out according to the principles expressed in the Declaration of Helsinki of 1964 and its later amendments.

\section{Population}

Data on persons newly diagnosed with HIV infection from January 1984 to December 2016 were selected from the HIV/AIDS database. Those who had left Taiwan, had an unknown HIV transmission route, unknown sex, age $<15$ years [25], incomplete records, or specific HIV transmission route (blood transfusion) were excluded.
8.15-9.01) at 4-12 months, and finally stabilized at 4.69 (95\% CI 4.57-4.80) thereafter (A). Therefore, the cut-off points for the time points of AIDS events were determined as: $\leq 3,4-12$, and $>12$ months after HIV diagnosis; $C I$ confidence interval

The route of HIV transmission for patients under 15 years may be due to mother-to-child transmission. The natural course for such patients is different to those who become infected with HIV through other transmission routes [IDU, men who have sex with men (MSM), and heterosexuals]. Therefore, patients under the age of 15 years were excluded. The enrolled patients were grouped into three at-risk categories: MSM, heterosexual people, and IDUs.

\section{Operational Definition of Variables}

The periods of HIV/AIDS diagnosis were divided into six categories according to the calendar 


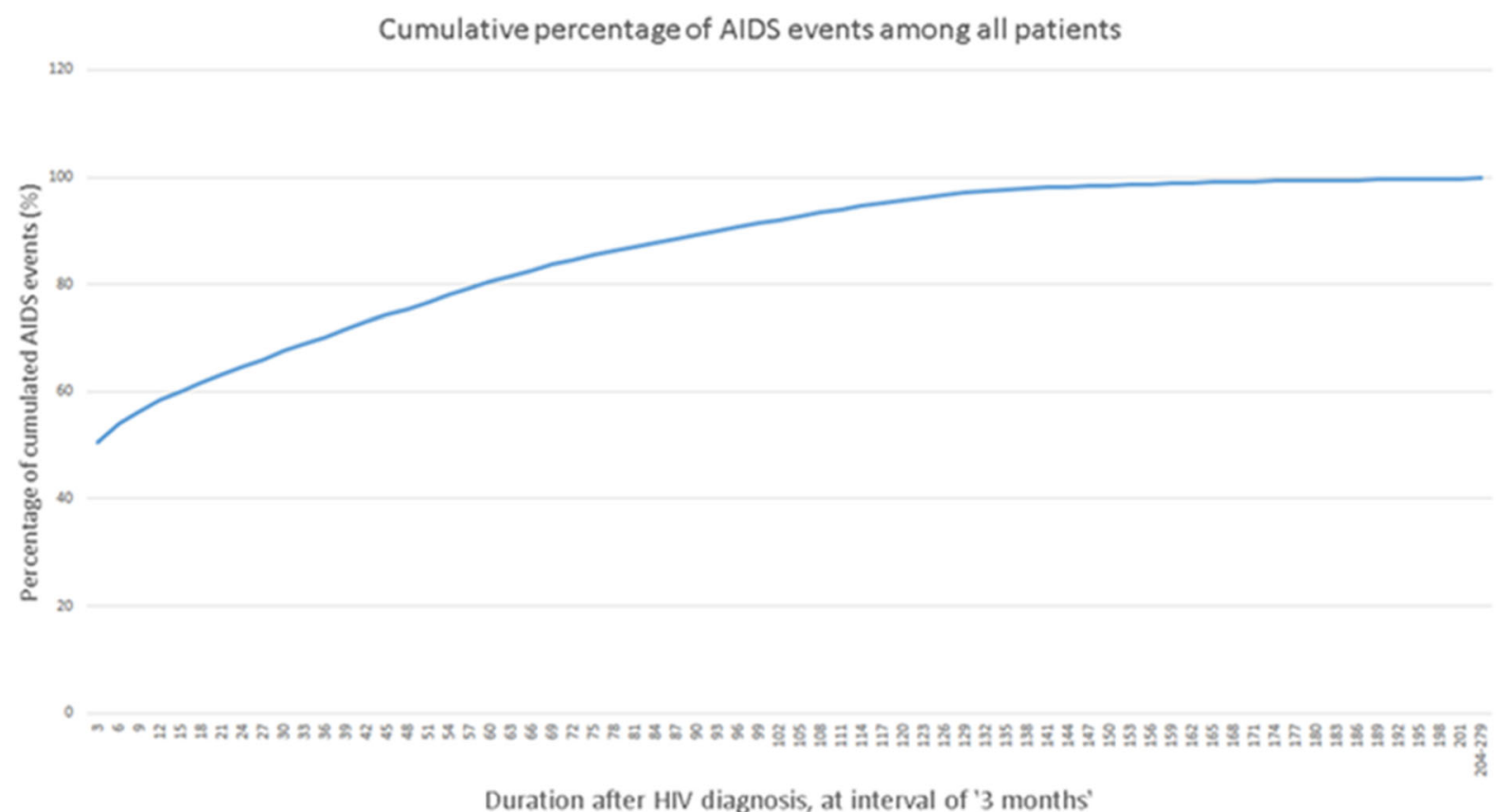

Fig. 2 Cumulative percentage of AIDS events among all patients. For $50.54 \%$ of patients who experienced an AIDS event, the event occurred within 3 months of HIV diagnosis; the rate then declined, with $80.5 \%$ developing AIDS within 5 years after HIV diagnosis

year of HIV/AIDS diagnosis [37]: 1984-1991 (pre-antiretroviral therapy), 1992-1996 (precART), 1997-2001 (early cART), 2002-2006 (mid-cART), 2007-2011 (late cART), and 2012-2016 (contemporary cART). Moreover, the HIV diagnosis regions were categorized into six administrative areas according to the Taiwan CDC NDSS: Taipei area, Northern Taiwan, Central Taiwan, Southern Taiwan, Kaoping area, and Eastern Taiwan [25].

The time points of AIDS events were divided into three categories according to the timing of their occurrence after HIV diagnosis: $\leq 3,4-12$, and $>12$ months (the determination of the cutoff points for these three AIDS event time points is described below).

\section{Statistical Analysis}

Clinicodemographic characteristics are reported as frequencies (\%), and comparisons between the three at-risk populations have been performed using the chi-square test for categorical variables.
First, to explore the dynamics of AIDS incidence after HIV diagnosis in the various at-risk populations, AIDS incidence was calculated by dividing the total number of AIDS events observed by the total person-years of observation constituting the risk period. The observation of each patient started from the date of HIV diagnosis and continued until death, the occurrence of an AIDS event, or 31 December 2016, whichever occurred first. The cut-off points for the three AIDS event time points were then determined using the incidence of AIDS events during postdiagnosis follow-up sessions conducted at 3-month intervals (Fig. 1A).

Second, the trends of AIDS incidence and evolving proportion of the three AIDS event time points in the various at-risk populations were evaluated across the six periods. In this part, the whole observation period of each patient also started from the date of HIV diagnosis and continued until death, the occurrence of an AIDS event, or 31 December 2016, whichever occurred first. We calculated the incidence of AIDS events in each period by dividing the total number of AIDS events 


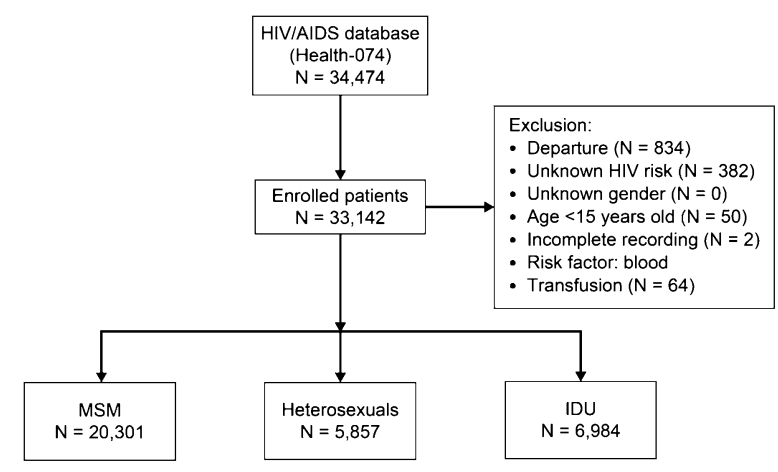

Fig. 3 Study flowchart

observed in each period by the total personyears of observation in each period. For each period, the observation started from 1 January of the first year of this period (if the patient was already enrolled in a previous period) or on the date of HIV diagnosis (if the patient was not enrolled in a previous period) and continued until 31 December of the final year of that period, the date at which an AIDS event occurred, or the date of death, whichever occurred first. We then presented the evolving proportion of three AIDS event time points among the patients who had AIDS events across the six periods. The Cochran-Armitage trend test was used to conduct trend analyses of the three dichotomized classes of AIDS event time points across the six periods.

Finally, to identify the determinants of the four AIDS statuses within 5 years after HIV diagnosis, the data of patients diagnosed with HIV from 1984 to 2011 were selected. In this part, each patient was observed until death, the occurrence of an AIDS event, or the 5-year mark after HIV diagnosis, whichever occurred first. A 5-year observation period was applied because $80 \%$ of AIDS events occurred within 5 years of HIV diagnosis (Fig. 2). The patients' AIDS status was classified into four categories according to their AIDS status within 5 years after HIV diagnosis: no AIDS occurrence, AIDS occurrence $\leq 3$ months, AIDS occurrence within 4-12 months, and AIDS occurrence $>12$ months. Multinomial logistic regression was used to identify determinants of the four AIDS statuses (with"no AIDS occurrence" being the reference). All covariates used in the univariable analysis were selected for subsequent multivariable logistic regression.

Odds ratios along with 95\% confidence intervals (CIs) were calculated to estimate the effects of each variable and directions of all associations. All tests were two-tailed, and $P<0.05$ was considered to be statistically significant. All data management and analyses were performed using SAS 9.4 (SAS Institute, Cary, NC, USA).

\section{RESULTS}

\section{Patient Characteristics}

A total of 33,142 patients were enrolled [MSM: 20,301 (61.25\%); heterosexual people: 5,857 (17.67\%); and IDUs: 6984 (21.07\%)] (Fig. 3). Most patients were men (94.4\%), unmarried (78.6\%), and employed (61.1\%); received a diagnosis at designated HIV hospitals (62.7\%); and were aged $\leq 30$ years $(48.1 \%)$.

The three at-risk populations differed significantly in terms of clinicodemographic characteristics (Table 1).

\section{Overall AIDS Events During 1984-2016}

Of the 33,142 patients, 15,254 (46.0\%) had incident AIDS events during 150,309 personyears of observation, with the incidence being 10.15 events/100 person-years (95\% CI 10.00-10.30; Table 1). The proportion and incidence of AIDS were $44.9 \%$ and 11.52 events/ 100 person-years (95\% CI 11.30-11.75) in MSM, $61.7 \%$ and 14.86 events/100 person-years (95\% CI 14.42-15.32) in heterosexual people, and $36.3 \%$ and 4.95 events 100 person-years (95\% CI 4.76-5.14) in IDUs, respectively, and there was a significant difference between the three at-risk populations $(P<0.001$; Table 1$)$.

\section{Dynamics of AIDS Incidence over Time After HIV Diagnosis}

Overall, we observed a drastic decrease in AIDS incidence over time during the first 12 months 
Table 1 Clinicodemographic characteristics of 33,142 patients stratified into three at-risk populations

\begin{tabular}{|c|c|c|c|c|c|}
\hline & $\begin{array}{l}\text { Total } \\
n=33,142\end{array}$ & $\begin{array}{l}\text { MSM } \\
n=20,301\end{array}$ & $\begin{array}{l}\text { Heterosexuals } \\
n=\mathbf{5 8 5 7}\end{array}$ & $\begin{array}{l}\text { IDU } \\
n=6984\end{array}$ & $P$ value \\
\hline Median follow-up, person-year (IQR) & $3.25(7.67)$ & $2.42(5.75)$ & $1.49(6.83)$ & $8.33(6.67)$ & $<0.001$ \\
\hline Age group at HIV presentation, $n(\%)$ & & & & & $<0.001$ \\
\hline$\leq 30$ & $15,954(48.1)$ & $11,895(58.6)$ & $1,655(28.3)$ & $2404(34.4)$ & \\
\hline$>30$ to $\leq 50$ & $15,036(45.4)$ & $7869(38.8)$ & $2929(50)$ & $4238(60.7)$ & \\
\hline$>50$ & $2154(6.5)$ & $537(2.7)$ & $1273(21.7)$ & $342(4.9)$ & \\
\hline Male sex, $n(\%)$ & $31,137(94.4)$ & $20,301(100)$ & $4763(81.3)$ & $6,073(87)$ & $<0.001$ \\
\hline Period of HIV diagnosis, $n$ (\%) & & & & & $<0.001$ \\
\hline $1984-1991$ & $159(0.48)$ & $101(0.50)$ & $46(0.79)$ & $12(0.17)$ & \\
\hline $1992-1996$ & $887(2.68)$ & $432(2.13)$ & $420(7.17)$ & $35(0.5)$ & \\
\hline $1997-2001$ & $2359(7.12)$ & $1364(6.72)$ & $965(16.48)$ & $30(0.43)$ & \\
\hline $2002-2006$ & $9380(28.30)$ & $2892(14.25)$ & $1475(25.18)$ & $5013(71.78)$ & \\
\hline $2007-2011$ & $9026(27.23)$ & $5893(9.03)$ & $1576(26.91)$ & $1557(22.29)$ & \\
\hline $2012-2016$ & $11,331(34.19)$ & $9619(47.38)$ & $1375(23.48)$ & $337(4.83)$ & \\
\hline Marriage, $n(\%)$ & & & & & $<0.001$ \\
\hline Unknown & $82(0.2)$ & $53(0.2)$ & $12(0.2)$ & $17(0.2)$ & \\
\hline No & $26,040(78.6)$ & $19,304(95.1)$ & $2825(48.2)$ & $3911(56)$ & \\
\hline Yes & $7.020(21.2)$ & $944(4.7)$ & $3020(51.6)$ & $3056(43.8)$ & \\
\hline Occupation, $n$ (\%) & & & & & $<0.001$ \\
\hline Unknown & $1690(5.1)$ & $1284(6.3)$ & $288(4.9)$ & $118(1.7)$ & \\
\hline Student & $2740(8.3)$ & $2534(12.5)$ & $198(3.4)$ & $8(0.1)$ & \\
\hline Unemployment & $8457(25.5)$ & $2897(14.3)$ & $1387(23.7)$ & $4173(59.8)$ & \\
\hline Employment & $20,255(61.1)$ & $13,586(66.9)$ & $3984(68)$ & $2685(38.5)$ & \\
\hline Specimen source & & & & & $<0.001$ \\
\hline Designated HIV hospital & $20,785(62.7)$ & $15,882(78.2)$ & $3932(67.1)$ & $971(13.9)$ & \\
\hline Military screening & $965(2.9)$ & $839(4.1)$ & $108(1.8)$ & $18(0.3)$ & \\
\hline Blood donation & $5342(16.1)$ & $828(4.1)$ & $469(8)$ & $28(0.4)$ & \\
\hline Jail screening & $1325(4.0)$ & $286(1.4)$ & $237(4.1)$ & $4220(60.4)$ & \\
\hline Others & $4743(14.3)$ & $2466(12.2)$ & $1111(19)$ & $1747(25)$ & \\
\hline HIV diagnosis region, $n$ (\%) & & & & & $<0.001$ \\
\hline Taipei area & $13,209(39.9)$ & $9717(47.9)$ & $2074(35.4)$ & $1418(20.3)$ & \\
\hline Northern Taiwan & $4551(13.7)$ & $2564(12.6)$ & $786(13.4)$ & $1201(17.2)$ & \\
\hline Central Taiwan & $5613(16.9)$ & $3141(15.5)$ & $1093(18.7)$ & $1379(19.8)$ & \\
\hline
\end{tabular}


Table 1 continued

\begin{tabular}{|c|c|c|c|c|c|}
\hline & $\begin{array}{l}\text { Total } \\
n=33,142\end{array}$ & $\begin{array}{l}\text { MSM } \\
n=20,301\end{array}$ & $\begin{array}{l}\text { Heterosexuals } \\
n=\mathbf{5 8 5 7}\end{array}$ & $\begin{array}{l}\text { IDU } \\
n=6984\end{array}$ & $P$ value \\
\hline Southern Taiwan & $3403(10.3)$ & $1441(7.1)$ & $726(12.4)$ & $1236(17.7)$ & \\
\hline Kaoping area & $5780(17.4)$ & $3080(15.2)$ & $1018(17.4)$ & $1682(24.1)$ & \\
\hline Eastern Taiwan & $586(1.8)$ & $358(1.8)$ & $160(2.7)$ & $68(1)$ & \\
\hline $\begin{array}{l}\text { AIDS incidence, event } / 100 \text { person-years } \\
\quad(95 \% \mathrm{CI})\end{array}$ & $\begin{array}{l}10.15 \\
\quad(10.00-10.30)\end{array}$ & $\begin{array}{l}11.52 \\
\quad(11.30-11.75)\end{array}$ & $\begin{array}{l}14.86 \\
\quad(14.42-15.32)\end{array}$ & $\begin{array}{l}4.95 \\
(4.76-5.14)\end{array}$ & $<0.001$ \\
\hline \multicolumn{6}{|l|}{ AIDS event from 1984 to $2016, n$ (\%) } \\
\hline All AIDS events & $15,254(46.0)$ & $9106(44.9)$ & $3616(61.7)$ & $2532(36.3)$ & $<0.001$ \\
\hline Three time points of AIDS events ${ }^{\mathrm{a}}$ & & & & & $<0.001$ \\
\hline$\leq 3$ months & $7637(50.1)$ & $5189(57.0)$ & $2254(62.3)$ & $194(7.7)$ & \\
\hline $4-12$ months & $1485(9.7)$ & $995(10.9)$ & $285(7.9)$ & $205(8.1)$ & \\
\hline$>12$ months & $6132(40.2)$ & $2922(32.1)$ & 1077 (29.8) & $2133(84.2)$ & \\
\hline
\end{tabular}

$A I D S$ acquired immunodeficiency syndrome; $C I$ confidence interval; $H I V$ human immunodeficiency virus; IDU intravenous drug user; $I Q R$ interquartile range; $M S M$ men who have sex with men

${ }^{a}$ Indicates the proportion of the three time points of AIDS events among persons with HIV who experienced AIDS events during the observation period

after HIV diagnosis (Fig. 1A). However, the declining trends observed in the MSM and heterosexual people differed significantly from those observed in the IDUs (Fig. 1B).

The incidence of AIDS events after HIV diagnosis exhibited similar trends over time after HIV diagnosis among MSM and heterosexual populations. During the first 3 months after HIV diagnosis, the incidence was 137.25 events/100 person-years (95\% CI 133.57-141.02) for MSM and 246.62 events/100 person-years (95\% CI 236.68-256.98) for heterosexual people; at 4-12 months, the incidence declined steeply [9.88 events/100 personyears (95\% CI 9.29-10.52) for MSM and 11.77 events/100 person-years (95\% CI 10.48-13.21) for heterosexual people] and remained stable at low levels thereafter [4.48 events/100 personyears (95\% CI 4.32-4.64) for MSM and 5.13 events/100 person-years (95\% CI 4.83-5.45) for heterosexual people]. Among IDUs, the AIDS incidence after HIV diagnosis showed different patterns over time: during the first 3 months after HIV diagnosis, the incidence was 11.63 events/100 person-years (95\% CI 10.11-13.39); this decreased gradually to 4.23 events/100 person-years (95\% CI 3.69-4.85) at 4-12 months and then stabilized thereafter [4.77 events/100 person-years (95\% CI 4.57-4.98)] (Fig. 1B).

Overall, $50.1 \%, 9.7 \%$, and $40.2 \%$ of the AIDS events occurred $\leq 3,4-12$, and $>12$ months after HIV diagnosis, respectively. The distribution of AIDS event time points differed significantly between the three at-risk populations $(P<0.001$; Table 1). MSM and heterosexual people showed similar distribution of AIDS event time points: $57.0 \%$ versus 62.3 at the $\leq 3$ month time point, $10.9 \%$ versus $7.9 \%$ at the 4-12-month time point, and 32\% versus $29.8 \%$ at the $>12$-month time point. However, only $7.7 \%$ of the AIDS events occurred at the $\leq 3$ month time point, and $84.2 \%$ occurred at the $>12$-month time point in the IDUs. 
Table 2 Multinomial logistic regression modeling results of patients stratified by AIDS status within 5 years after HIV diagnosis

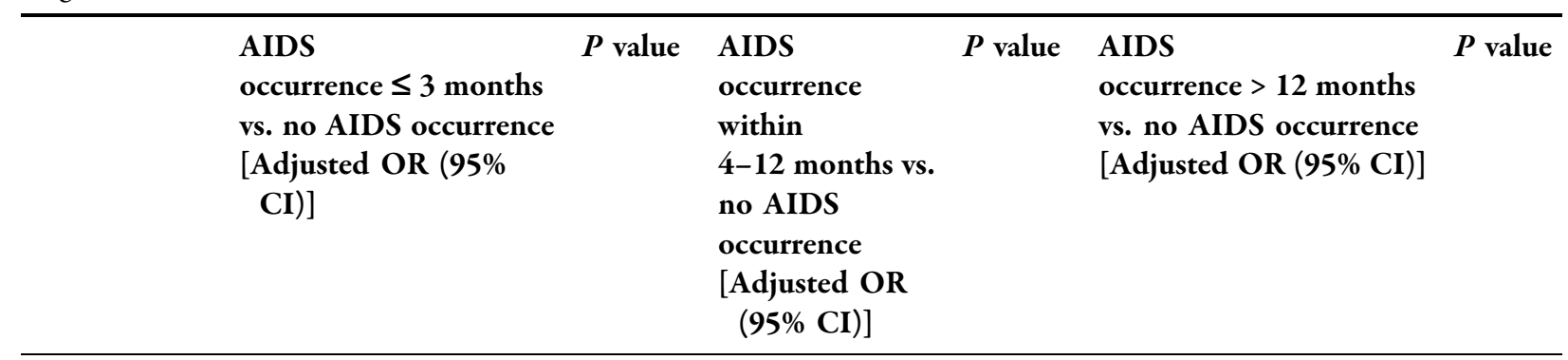

Age group

$$
\begin{array}{ll}
\leq 30 & \text { Reference } \\
>30-\text { to } \leq & 2.87(2.60-3.13) \\
50 & \\
>50 & 4.73(4.01-5.57)
\end{array}
$$

Gender

Female

Reference

Male

$1.60(1.34-1.91)$

At-risk population

$\begin{array}{ll}\text { MSM } & \text { Reference } \\ \begin{array}{l}\text { Heterosexual } \\ \text { contact }\end{array} & 1.70(1.53-1.89)\end{array}$

IDU

$0.12(0.10-0.14)$

Period of HIV diagnosis

$$
\begin{array}{ll}
1984-1991 & \text { Reference } \\
1992-1996 & 1.64(0.96-2.79) \\
1997-2001 & 1.22(0.73-2.04) \\
2002-2006 & 1.45(0.88-2.43) \\
2007-2011 & 2.41(1.45-4.00)
\end{array}
$$

Marriage

$\begin{array}{ll}\text { No } & \text { Reference } \\ \text { Unknown } & 2.38(0.76-7.42) \\ \text { Yes } & 1.04(0.93-1.17)\end{array}$

Employment

Reference

$<0.001$

$1.56(1.32-1.85)$

$<0.001$

Reference

$<0.001 \quad 2.65(1.95-3.61) \quad<0.001$

$1.52(1.25-1.84)$

$<0.001$

Reference

Reference

$<0.001 \quad 1.09(0.90-1.49)$

0.573

$1.21(1.01-1.43)$

0.034

Reference

Reference

$<0.001 \quad 1.09(0.88-1.35)$

$0.427 \quad 1.05(0.92-1.19)$

0.457

$<0.001$

$0.33(0.25-0.44)$

$<0.001$

$0.53(0.45-0.61)$

Reference

$0.07 \quad 4.17$

$$
\text { (0.99-17.52) }
$$

$0.458 \quad 1.22(0.29-5.10)$

$0.148 \quad 3.14$

$(0.77-12.84)$

$<0.001 \quad 4.79$

$(1.18-19.58)$
0.678

$0.051 \quad 0.90(0.56-1.46)$

$0.790 \quad 0.46(0.29-0.73)$

$<0.001$

$0.112 \quad 1.21(0.78-1.88)$

0.387

$0.029 \quad 1.05(0.68-1.63)$

0.824

Reference

Reference

$0.137 \quad 1.93$

$0.546 \quad 0.54(0.07-4.38)$

0.561

$(0.23-16.15)$

$0.4721 .05(0.85-1.30)$

$0.664 \quad 1.01(0.90-1.13)$

0.847

No

Reference

Reference 
Table 2 continued

\begin{tabular}{|c|c|c|c|c|c|c|}
\hline & $\begin{array}{l}\text { AIDS } \\
\text { occurrence } \leq 3 \text { months } \\
\text { vs. no AIDS occurrence } \\
\text { [Adjusted OR }(95 \% \\
\text { CI }) \text { ] }\end{array}$ & $P$ value & $\begin{array}{l}\text { AIDS occurrence } \\
\text { within } \\
\text { 4-12 months vs. no } \\
\text { AIDS occurrence } \\
\text { [Adjusted OR ( } 95 \% \\
\text { CI)] }\end{array}$ & $P$ value & $\begin{array}{l}\text { AIDS } \\
\text { occurrence > } 12 \text { months } \\
\text { vs. no AIDS occurrence } \\
\text { [Adjusted OR }(95 \% \mathrm{CI})]\end{array}$ & $P$ value \\
\hline Student & $0.57(0.47-0.69)$ & $<0.001$ & $1.19(0.88-1.60)$ & 0.250 & $0.74(0.62-0.90)$ & 0.003 \\
\hline Unknown & $0.95(0.77-1.19)$ & 0.673 & $0.91(0.59-1.41)$ & 0.673 & $1.03(0.79-1.35)$ & 0.822 \\
\hline Yes & $0.72(0.65-0.79)$ & $<0.001$ & $0.86(0.72-1.03)$ & 0.107 & $0.93(0.84-1.03)$ & 0.147 \\
\hline \multicolumn{7}{|c|}{ Specimen source } \\
\hline $\begin{array}{l}\text { HIV } \\
\text { referral } \\
\text { center }\end{array}$ & Reference & & Reference & & Reference & \\
\hline $\begin{array}{l}\text { Military } \\
\text { screening }\end{array}$ & $0.27(0.19-0.40)$ & $<0.001$ & $0.89(0.41-1.16)$ & 0.164 & $1.39(1.10-1.77)$ & 0.007 \\
\hline $\begin{array}{l}\text { Blood } \\
\text { donation } \\
\text { center }\end{array}$ & $0.11(0.08-0.15)$ & $<0.001$ & $0.85(0.61-1.18)$ & 0.323 & $1.07(0.89-1.28)$ & 0.377 \\
\hline $\begin{array}{l}\text { Jail } \\
\text { screening }\end{array}$ & $0.11(0.08-0.15)$ & $<0.001$ & $0.95(0.71-1.27)$ & 0.716 & $0.92(0.79-1.07)$ & 0.261 \\
\hline Others & $0.53(0.47-0.60)$ & $<0.001$ & $1.14(0.93-1.40)$ & 0.202 & $1.11(0.98-1.25)$ & 0.105 \\
\hline \multicolumn{7}{|c|}{ HIV diagnosis region } \\
\hline $\begin{array}{l}\text { Kaoping } \\
\text { area }\end{array}$ & Reference & & Reference & & Reference & \\
\hline $\begin{array}{l}\text { Taipei } \\
\text { area }\end{array}$ & $0.67(0.60-0.75)$ & $<0.001$ & $0.90(0.73-1.12)$ & 0.336 & $1.03(0.91-1.17)$ & 0.642 \\
\hline $\begin{array}{l}\text { Northern } \\
\text { Taiwan }\end{array}$ & $1.00(0.87-1.16)$ & 0.971 & $1.30(1.01-1.67)$ & 0.042 & $1.30(1.01-1.67)$ & $<0.001$ \\
\hline $\begin{array}{l}\text { Central } \\
\text { Taiwan }\end{array}$ & $1.02(0.889-1.16)$ & 0.828 & $1.02(0.80-1.31)$ & 0.863 & $1.06(0.92-1.22)$ & 0.392 \\
\hline $\begin{array}{l}\text { Southern } \\
\text { Taiwan }\end{array}$ & $1.31(1.12-1.53)$ & 0.004 & $1.19(0.90-1.58)$ & 0.229 & $1.31(1.12-1.53)$ & $<0.001$ \\
\hline $\begin{array}{l}\text { Eastern } \\
\text { Taiwan }\end{array}$ & $1.61(1.21-2.14)$ & 0.001 & $1.47(0.84-2.57)$ & 0.178 & $1.64(1.21-2.24)$ & 0.002 \\
\hline
\end{tabular}

$A I D S$ acquired immunodeficiency syndrome; $C I$ confidence interval; $H I V$ human immunodeficiency virus; $I D U$ intravenous drug user; $M S M$ men who have sex with men; $O R$ odds ratio 

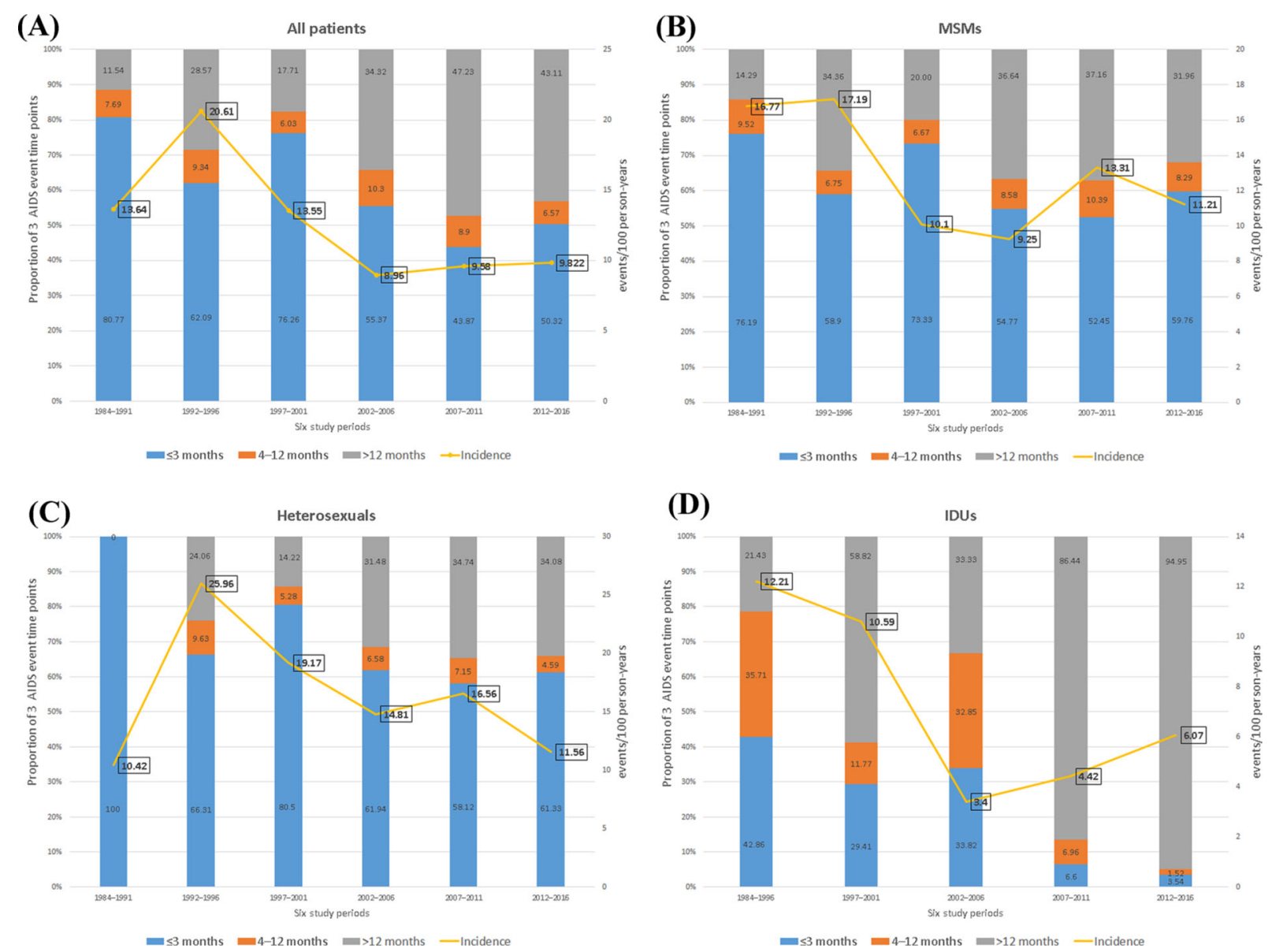

Fig. 4 Trends of AIDS incidence across six periods and proportion of AIDS events at three time points among all HIVpositive patients who experienced AIDS events during observation period (A) and in each at-risk population: B MSM, C heterosexual people, and D IDUs

\section{Trends of AIDS Incidence and Evolution of the Proportion of the Three AIDS Event Time Points During 1984-2016}

The overall AIDS incidence fluctuated during 1984-2016. The incidence peaked during 1992-1996 (20.61 events/100 person-years), after which it declined until 2002-2006 and then finally stabilized during 2002-2016 (8.96-9.82 events/100 person-years). The proportion of AIDS events at the $\leq 3$-month time point peaked during 1984-1991 (80.77\%), then declined, and finally remained stable during 2002-2016 (43.87\%-55.37\%) $\quad(P \quad$ for trend $<0.001)$. The proportion of AIDS events at the $>12$-month time point increased from
$11.54 \%$ during $1984-1991$ to $43.11 \%$ during 2012-2016 ( $P$ for trend $<0.001$; Fig. 4A).

The incidence and event trends observed in MSM and heterosexual people differed from those observed in IDUs (Fig. 4B-D). Among MSM and heterosexual people, the AIDS incidence peaked during 1992-1996 (17.19 and 24.06 events/100 person-years, respectively) and then declined thereafter, with a small peak during 2007-2011 (13.31 and 16.56 events/100 person-years, respectively). The proportion of AIDS events at the $\leq 3$-month time point fluctuated but remained at $>50 \%$ among MSM ( $P$ for trend $=0.968$ ) and at $>55 \%$ among heterosexual people ( $P$ for trend $=0.985$ ) during 1984-2016. The proportion of AIDS events at the $>12$-month time point increased 
significantly $(0 \%-34.08 \%, P$ for trend $<0.001$; Fig. 4C) among heterosexual people, but the increase was not significant among MSM $(14.29-31.96 \%, \quad P$ for trend $=0.985)$ during 1984-2016.

However, the trends were considerably different among IDUs. The AIDS incidence declined from 1984-1996 (12.21 events/100 person-years) to 2002-2006 (3.40 events/100 person-years) and increased thereafter (4.42-6.07 events/100 person-years). The proportions of AIDS events at the $\leq 3$-month time point $(42.86 \%-3.54 \%$; $P$ for trend $<0.001)$ and $4-12$-month time point $(35.71 \%-1.52 \%$; $P$ for trend $<0.001$ ) decreased during 1984-2016. The proportion of AIDS events at the $>12$ month time point increased during 1984-2016 $(21.43 \%-94.95 \%, P$ for trend $<0.001$; Fig. 4D).

\section{Determinants of AIDS Status Within 5 years of HIV Diagnosis}

Finally, 21,811 patients who were diagnosed with HIV from 1984 to 2011 were selected for analysis of determinants of AIDS status within 5 years of HIV diagnosis. For AIDS $\leq 3$ months (vs. no AIDS), positive determinants were older age (vs. age $\leq 30$ years), male sex, heterosexuality (vs. MSM), the period 2007-2011 (vs. 1984-1991), and the Southern/Eastern regions of Taiwan (vs. the Kaoping area). Negative determinants were IDUs (vs. MSM), student/ employed status (vs. unemployed status), military screening/blood donation center/jail screening/others (vs. HIV referral center), and the Taipei area (vs. Kaoping area) (Table 2).

For AIDS within 4-12 months (vs. no AIDS), positive determinants were older age, the period 2007-2011, and the Northern region of Taiwan. Negative determinants were IDUs (Table 2).

For AIDS > 12 months (vs. no AIDS), positive determinants were older age, male sex, military screening (vs. HIV referral center), and the Northern/Southern/Eastern regions of Taiwan. Negative determinants were IDUs, the period 1997-2001, and student status (Table 2).

\section{DISCUSSION}

This study is the first to explore the trends of different AIDS event time points after HIV diagnosis in various at-risk populations in the past 3 decades. The HIV epidemic in Taiwan is similar to that in other Asian-Pacific countries, North America, and Western Europe $[27,28,38,39]$, where MSM form the predominant HIV transmission group; thus, our findings have global interest. Because our study had a longer follow-up duration than that of a previous study ( 2 years) [25], we observed more patients ( $46 \%$ vs. $27.4 \%$, respectively) reporting an AIDS event, with $50.1 \%$ of the patients developing AIDS within 3 months of HIV diagnosis and $40.2 \%$ developing AIDS 1 year after diagnosis. These findings indicate a high burden of AIDS events in Taiwan and, thus, to reduce the AIDS epidemic in Taiwan, AIDS prevention strategies that are tailored to the distinct evolution of the time points of AIDS events in various at-risk populations are required.

An AIDS event occurring within 3 months of HIV diagnosis is consistent with the definition of late presentation of HIV (late presenter) $[5,27,28]$. The etiologies of AIDS at 4-12 months and $>12$ months after HIV diagnosis may overlap but may not be identical due to the differences in the AIDS incidence and factors influencing AIDS status within 5 years of HIV diagnosis. AIDS events occurring 4-12 months after HIV diagnosis suggest late cART initiation $[30,40]$ or reflect an advanced immunocompromised status, and such patients may develop immune reconstitution inflammatory syndrome after cART treatment [41-43]. However, AIDS events at $>12$ months after HIV diagnosis are likely to be related to poor linkage to HIV care or poor adherence to cART [34, 35].

Although the observed AIDS incidence declined abruptly during 1997-2001 after the introduction of cART, the trend stabilized thereafter. These findings are consistent with previous studies, which reported a drastic decline in the incidence of AIDS-defining opportunistic diseases in HIV-infected patients in 1992-1997, a more gradual decline in 
1998-2002, and then a stabilization at a low level of incidence in 2003-2007 [37, 40, 44, 45]. Considering the lack of considerable change during 2002-2016, further interventions to reduce the AIDS burden are imperative. Throughout the six periods, the proportion of AIDS events occurring $\leq 3$ months after HIV diagnosis declined but remained at $>50 \%$ among MSM and $>55 \%$ among heterosexual people, but those occurring $>12$ months after HIV diagnosis emerged as a new threat in heterosexual people $[0 \%-34.08 \% \quad(P$ for trend $<0.001)$, and $>30 \%$ since 2002-2006] and IDUs $[21.43 \%-94.95 \%$ ( $P$ for trend $<0.001$ ), and $>80 \%$ since 2007-2011]. This finding implies that enhancing early diagnosis among people with sexual contact and optimizing adherence to the HIV care continuum among heterosexual people and IDUs should be priorities for further AIDS prevention strategies. Although the proportion of AIDS events occurring within 4-12 months after HIV diagnosis did not change among the people with sexual contact, they constituted $5 \%-10 \%$ of AIDS events; however, in IDUs, these events decreased throughout the study period.

Since 1997, aVCT has been prioritized in HIV testing to improve early HIV diagnosis in Taiwan, and regular linkage to aVCT has been shown to effectively enhance the early diagnosis of HIV [46]. In our recent investigation of compliance to aVCT cascade among 572 patients with HIV infection in Taiwan (homosexual: $79.6 \%$; bisexual: $13.6 \%$; heterosexual: $6.1 \%)$, only $60.5 \%$ had ever received aVCT before HIV diagnosis, and 30.8\% regularly received aVCT. Barriers to aVCT cascade include a low perceived risk of HIV infection and the fear of discrimination or stigma [46]. Consistent with other studies [5, 47], late presenters are even more common among heterosexual populations than among MSM; this is attributable to the lower HIV testing rates among heterosexual people because of the low perceived risk [48, 49]. More alarming, however, is the high proportion of AIDS events in MSM due to late presentation. MSM are the predominant HIV risk group and the main target of aVCT strategies. Therefore, reducing the prevalence of late presenters among people with sexual contact requires expanded HIV screening strategies as part of routine care or opt-out testing (as opposed to opt-in testing) in healthcare and non-healthcare settings, and it is important that these strategies reach key populations $[50,51]$. By contrast, late presentation was not prevalent among IDUs, possibly due to the predominance of the indolent HIV CRF07_BC strain among IDUs in Taiwan $[52,53]$ and the active surveillance of HIV among prison inmates since 1991 [54, 55]. Our findings also support the importance of routine HIV testing (i.e., military screening, blood donation centers, and jail screening) in early HIV detection $[51,56]$.

Nearly one-third of AIDS events among MSM and heterosexual populations since 2002 and $>80 \%$ of AIDS events among IDUs since 2007 occurred $>12$ months after HIV diagnosis, despite the availability of universal access to care and cART therapy since the mid-1990s. Several barriers may hinder successful engagement and retention in the HIV care continuum, such as late cART initiation [30,40], changing thresholds of cART initiation [31, 32], and suboptimal adherence to cART $[34,35,57]$. The problem may worsen after rapid cART initiation [17] or even same-day cART [58], considering the increased rate of loss to follow-up and reduced rate of retention among same-day initiators $[59,60]$.

Although HIV-positive IDUs had a lower risk for each AIDS status than the MSM, they had a rapid increase in the proportion of AIDS events occurring $>12$ months after HIV diagnosis (33.3\% in 2002-2006 to $86.4 \%$ in 2007-2011). This may largely be due to the decrease in the number of newly diagnosed HIV-positive IDUs after the implementation of harm reduction therapy in Taiwan in 2005 [61], resulting in a decrease in the proportion of AIDS events occurring $\leq 12$ months after HIV diagnosis. Therefore, to further prevent AIDS events among HIV-positive IDUs diagnosed since 2007, the government should focus on AIDS events $>12$ months after HIV diagnosis. IDUs have been shown to have poor adherence to cART $[62,63]$, a high rate of HIV care discontinuity [64-66], a high rate of physician deferral of cART prescriptions [67], and delayed cART 
initiation independently of clinical eligibility [68] due to criminalization and socioeconomic marginalization. Accordingly, measures should be taken to reduce the criminalization and mitigate the socioeconomic marginalization of IDUs to improve their access to and continuity of the HIV care continuum.

The present findings also confirm that older age was a risk factor for each AIDS status $[28,69,70]$. Older PWH have a higher risk of being late presenters due to the lower perception of HIV risk [71], lack of physician awareness regarding HIV infection [72], and underestimation of HIV risk behaviors [73]; moreover, they have a higher risk of AIDS events during follow-up, which is likely due to missed clinic visits [70].

Notably, PWH diagnosed through military screening were more likely to have AIDS $>12$ months after HIV diagnosis than those diagnosed at HIV referral centers. This may be due to a passive attitude towards the perceived risk of HIV and engagement in HIV care among PWH diagnosed through military screening in contrast to those who took the initiative to visit an HIV referral center for HIV diagnosis and medical care. Additional studies are required to investigate the influence of specimen sources on other clinical outcomes, such as virological and immunological responses, retention rate in HIV care, and mortality. Disparities in sociodemographic characteristics (gender, employment, and region of HIV diagnosis) with regards to the progression to various AIDS statuses within 5 years of HIV diagnosis also indicate the necessity of reallocating resources and redoubling efforts to implement appropriate and effective interventions.

The major strength of this study is its nationwide scope and population-based design along with the extended and nearly complete follow-up over the past 3 decades, which minimized selection and referral biases. However, this study has several limitations. First, several variables, such as cART prescription, different cART combinations, comorbidities, $\mathrm{CD}^{+}$cell count, viral load, and compliance to the HIV care continuum, could not be analyzed because the relevant data were not included in the HIV/ AIDS dataset. Therefore, further studies are warranted to investigate the influence of these variables on AIDS status within 5 years of HIV diagnosis. Second, only the first AIDS event was recorded, which precluded any analysis of subsequent AIDS events after recovery from the first event. This may have led to an underestimation of the incidence of AIDS events. Third, in the HIV/AIDS dataset, the classification of at-risk population (MSM, heterosexuals, IDUs) depend on the responses from the patients. However, some heterosexual patients may be reluctant to disclose MSM behaviors due to stigma at enrollment, leading to misclassification of atrisk populations. Finally, clinical AIDS diagnosis reporting may not have been complete, leading to a potential underestimation of AIDS events.

\section{CONCLUSIONS}

We have demonstrated a significant burden of AIDS events in Taiwan. Although the incidence decreased significantly after the introduction of cART, the epidemic has been stable since 2002 . Considering the disparity in the trends of the incidence and evolution of the AIDS event time points in various at-risk populations, as well as the relatively clear understanding of the factors associated with different AIDS statuses within 5 years of HIV diagnosis, additional active strategies tailored to different AIDS event time points are imperative to control the AIDS epidemic in at-risk populations in Taiwan. Enhancing early diagnosis among people with sexual contact and optimizing adherence to the HIV care continuum among heterosexual people and IDUs should be priorities of further AIDS prevention strategies.

\section{ACKNOWLEDGEMENTS}

Funding. The design of the study, editorial writing support, the collection, analysis, interpretation of data, and the Rapid Service Fee, were supported by the Ministry of Science and Technology, Taiwan, R.O.C. under grant no. MOST 108-2314-B-037-050 and Kaohsiung Municipal Siaogang Hospital, Taiwan, R.O.C. 
under grant no. H-108-006 and H109-009. We thank the Center for Medical Informatics and Statistics of Kaohsiung Medical University for providing administrative and funding support.

Medical writing, editorial, and other assistance. The authors thank Wallace Academic Editing for editing the manuscript.

Authorship. All named authors meet the International Committee of Medical Journal Editors (ICMJE) criteria for authorship for this article, take responsibility for the integrity of the work as a whole, and have given their approval for this version to be published.

Authorship contributions. Concept and study design: Chun-Yuan Lee, Pei-Hua Wu, FuWen Liang. Data acquisition: all authors. Analyses of the data: Chun-Yuan Lee, Pei-Hua Wu. Statistics: Chun-Yuan Lee, Pei-Hua Wu. Supervision: Po-Liang Lu, Fu-Wen Liang. Manuscript preparation: Chun-Yuan Lee, Pei-Hua Wu. Review and approval: all authors.

Disclosures. All authors declare that they have no competing interests.

Compliance with ethics guidelines. This study was approved by the Institutional Review Board of Kaohsiung Medical University Hospital (KMUHIRB-E (II)-20200084). The requirement for informed consent was waived. The study was carried out according to the principles expressed in the Declaration of Helsinki of 1964 and its later amendments.

Data availability. All data containing relevant information to support the study findings are provided in the manuscript.

Open Access. This article is licensed under a Creative Commons Attribution-NonCommercial 4.0 International License, which permits any non-commercial use, sharing, adaptation, distribution and reproduction in any medium or format, as long as you give appropriate credit to the original author(s) and the source, provide a link to the Creative Commons licence, and indicate if changes were made. The images or other third party material in this article are included in the article's Creative Commons licence, unless indicated otherwise in a credit line to the material. If material is not included in the article's Creative Commons licence and your intended use is not permitted by statutory regulation or exceeds the permitted use, you will need to obtain permission directly from the copyright holder. To view a copy of this licence, visit http:// creativecommons.org/licenses/by-nc/4.0/.

\section{REFERENCES}

1. Sarah LR-J. Timeline: AIDS pathogenesis: what have two decades of HIV research taught us? Nat Rev Immunol. 2003;3:343-8.

2. Hønge BL, Jespersen S, Aunsborg J, et al. High prevalence and excess mortality of late presenters among HIV-1, HIV-2 and HIV-1/2 dually infected patients in Guinea-Bissau - a cohort study from West Africa. Pan Afr Med J. 2016;25:40.

3. Sabin CA, Smith CJ, Gumley H, et al. Late presenters in the era of highly active antiretroviral therapy: uptake of and responses to antiretroviral therapy. AIDS. 2004;18:2145-51.

4. Sterne JA, May M, Costagliola D, et al. Timing of initiation of antiretroviral therapy in AIDS-free HIV-1-infected patients: a collaborative analysis of 18 HIV cohort studies. Lancet. 2009;373:1352-63.

5. Mocroft A, Lundgren JD, Sabin ML, et al. Risk factors and outcomes for late presentation for HIVpositive persons in Europe: results from the Collaboration of Observational HIV Epidemiological Research Europe Study (COHERE). PLOS Med. 2013;10: e1001510.

6. Nacher M, Adenis A, Abboud P, et al. HIV patients dying on anti-tuberculosis treatment: are undiagnosed infections still a problem in French Guiana? BMC Res Notes. 2020;13:209.

7. Alebel A, Engeda EH, Kelkay MM, et al. Mortality rate among HIV-positive children on ART in Northwest Ethiopia: a historical cohort study. BMC Public Health. 2020;20:1303.

8. Skarbinski J, Rosenberg E, Paz-Bailey G, et al. Human immunodeficiency virus transmission at each step of the care continuum in the United States. JAMA Intern Med. 2015;175:588-96. 
9. Marks G, Crepaz N, Janssen RS. Estimating sexual transmission of HIV from persons aware and unaware that they are infected with the virus in the USA. AIDS. 2006;20:1447-50.

10. Sisay MM, Ayele TA, Gelaw YA, et al. Incidence and risk factors of first-line antiretroviral treatment failure among human immunodeficiency virus-infected children in Amhara regional state, Ethiopia:a retrospective follow-up study. BMJ Open. 2018;8: e019181.

11. Florence E, Lundgren J, Dreezen C, et al. Factors associated with a reduced CD4 lymphocyte count response to HAART despite full viral suppression in the EuroSIDA study. HIV Med. 2003;4:255-62.

12. O'Connor EE, Zeffiro TA, Lopez OL, Becker JT. Differential effects of an AIDS defining illness and chronic HIV infection on gray matter volume. Clin Infect Dis. 2020. https://doi.org/10.1093/cid/ ciaa1552.

13. Prasitsuebsai W, Kariminia A, Puthanakit T, et al. Impact of antiretroviral therapy on opportunistic infections of HIV-infected children in the therapeutic research, education and AIDS training Asia pediatric HIV observational database. Pediatr Infect Dis J. 2014;33:747-52.

14. Ledergerber B, Egger M, Erard V, et al. AIDS-related opportunistic illnesses occurring after initiation of potent antiretroviral therapy: the Swiss HIV Cohort Study. JAMA. 1999;282:2220-6.

15. Detels R, Muñoz A, McFarlane G, et al. Effectiveness of potent antiretroviral therapy on time to AIDS and death in men with known HIV infection duration. Multicenter AIDS Cohort Study Investigators. JAMA. 1998;280:1497-503.

16. Ayele HT, Mourik MS, Debray TP, Bonten MJ. Isoniazid prophylactic therapy for the prevention of tuberculosis in HIV infected adults: a systematic review and meta-analysis of randomized trials. PLoS ONE. 2015;10: e0142290.

17. Rosen S, Maskew M, Fox MP, et al. Initiating antiretroviral therapy for HIV at a patient's First Clinic Visit: the RapIT randomized controlled trial. PLOS Med. 2016;13: e1002015.

18. Wilton J, Liu J, Sullivan A, et al. Trends in HIV care cascade engagement among diagnosed people living with HIV in Ontario, Canada: a retrospective population-based cohort study. PLoS ONE. 2019;14: e0210096.

19. UNAIDS. Global HIV \& AIDS statistics-2020 fact sheet. 2020. https://www.unaids.org/en/resources/ fact-sheet. Accessed 23 Dec 2020.
20. Melkamu MW, Gebeyehu MT, Afenigus AD, et al. Incidence of common opportunistic infections among HIV-infected children on ART at Debre Markos referral hospital, Northwest Ethiopia: a retrospective cohort study. BMC Infect Dis. 2020;20: 50.

21. Lajoie MRB, Drouin O, Bartlett G, et al. Incidence and prevalence of opportunistic and other infections and the impact of antiretroviral therapy among HIV-infected children in low- and middleincome countries: a systematic review and metaanalysis. Clin Infect Dis. 2016;62:1586-94.

22. Temesgen B, Kibret GD, Alamirew NM, et al. Incidence and predictors of tuberculosis among HIVpositive adults on antiretroviral therapy at Debre Markos referral hospital, Northwest Ethiopia:a retrospective record review. BMC Public Health. 2019;19:1566.

23. Liu WD, Tsai WC, Hsu WT, et al. Impact of initiation of combination antiretroviral therapy according to the WHO recommendations on the survival of HIV-positive patients in Taiwan. J Microbiol Immunol Infect. 2020;53:936-45.

24. Centers for Disease Control. DoH ROCT. AIDS control program. In: Centers Dis Control DoH, R. O. C. (Taiwan). 2007. http://www.cdc.gov.tw/ english/info.aspx?treeid=

e79c7a9e1e9b1cdf\&nowtreeid= e02c24f0dacdd729\&tid=7D01A79F5FD3B63D. Accessed 23 Dec 2020.

25. Lee CY, Jen IA, Lan YC, et al. AIDS incidence trends at presentation and during follow-up among HIVat-risk populations: a 15-year nationwide cohort study in Taiwan. BMC Public Health. 2018;18:589.

26. Lohse N, Obel N. Update of survival for persons with HIV infection in Denmark. Ann Intern Med. 2016;165:749-50.

27. Cheng W, Tang W, Han Z, et al. Late presentation of HIV infection: prevalence, trends, and the role of HIV testing strategies in Guangzhou, China, 2008-2013. Biomed Res Int. 2016;2016:1631878.

28. Jeong SJ, Italiano C, Chaiwarith R, et al. Late presentation into care of HIV disease and its associated factors in Asia: results of TAHOD. AIDS Res Hum Retrovir. 2016;32:255-61.

29. Duff P. Prevention of opportunistic infections in women with HIV infection. Clin Obstet Gynecol. 2019;62:816-22.

30. Lin KY, Cheng CY, Li CW, et al. Trends and outcomes of late initiation of combination antiretroviral therapy driven by late presentation among 
HIV-positive Taiwanese patients in the era of treatment scale-up. PLoS ONE. 2017;12: e0179870.

31. INSIGHT START Study Group, Lundgren JD, Babiker AG, et al. Initiation of antiretroviral therapy in early asymptomatic HIV infection. N Engl J Med. $2015 ; 373: 795-807$.

32. TEMPRANO ANRS 12136 Study Group, Danel C, Moh R, et al. A trial of early antiretrovirals and isoniazid preventive therapy in Africa. N Engl J Med. 2015;373:808-22.

33. Anastos K, Barrón Y, Miotti P, et al. Risk of progression to AIDS and death in women infected with HIV-1 initiating highly active antiretroviral treatment at different stages of disease. Arch Intern Med. 2002;162:1973-80.

34. Solomon FB, Angore BN, Koyra HC, et al. Spectrum of opportunistic infections and associated factors among people living with HIV/AIDS in the era of highly active anti-retroviral treatment in Dawro Zone hospital: a retrospective study. BMC Res Notes. 2018;11:604.

35. Toh HS, Yang CT, Yang KL, et al. Reduced economic burden of AIDS-defining illnesses associated with adherence to antiretroviral therapy. Int J Infect Dis. 2020;91:44-9.

36. Centers for Disease Control and Prevention. 1993 revised classification system for HIV infection and expanded surveillance case definition for AIDS among adolescents and adults. Morb Mortal Wkly Rep. 1992;41:1-19.

37. Buchacz K, Baker RK, Palella FJ Jr, et al. AIDSdefining opportunistic illnesses in US patients: a cohort study. AIDS. 2010;24:1549-59.

38. Beyrer C, Baral SD, van Griensven F, et al. Global epidemiology of HIV infection in men who have sex with men. Lancet. 2012;380:367-77.

39. Althoff KN, Gange SJ, Klein MB, et al. Late presentation for human immunodeficiency virus care in the United States and Canada. Clin Infect Dis. 2010;50:1512-20.

40. Kim MJ, Chang HH, Kim SI, et al. Trend of CD4+ cell counts at diagnosis and initiation of highly active antiretroviral therapy (HAART): Korea HIV/ AIDS cohort study, 1992-2015. Infect Chemother. 2017;49:101-8.

41. Yen YF, Chen M, Jen I-A, et al. Short- and long-term risks of highly active antiretroviral treatment with incident opportunistic infections among people living with HIV/AIDS. Sci Rep. 2019;9:3476.
42. Cotton MF, Rabie H, Nemes E, et al. A prospective study of the immune reconstitution inflammatory syndrome (IRIS) in HIV-infected children from high prevalence countries. PLoS ONE. 2019;14: e0211155.

43. Pérez-Rueda $M$, Hernández-Cabrera $M$, FrancésUrmeneta A, et al. Immune reconstitution inflammatory syndrome in HIV-infected immigrants. Am J Trop Med Hyg. 2017;97:1072-7.

44. Sezgin E, Van Natta ML, Thorne JE, et al. Longitudinal Studies of the Ocular Complications of AIDS (SOCA) Research Group. Secular trends in opportunistic infections, cancers and mortality in patients with AIDS during the era of modern combination antiretroviral therapy. HIV Med. 2018;19: 411-9.

45. Brooks JT, Kaplan JE, Holmes KK, et al. HIV-associated opportunistic infections-going, going, but not gone: the continued need for prevention and treatment guidelines. Clin Infect Dis. 2009;48: 609-11.

46. Lee CY, Wu PH, Tsai JJ, et al. Cascade analysis of anonymous voluntary HIV counseling and testing. Among patients with HIV infection in Taiwan. AIDS Patient Care STDs. 2020;34:303-15.

47. O'Connell S, Enkelmann J, Sadlier C, Bergin C. Late HIV presentation: missed opportunities and factors associated with a changing pattern over time. Int J STD AIDS. 2017;28:814-21.

48. Finlayson TJ, Le B, Smith A, et al. HIV risk, prevention, and testing behaviors among men who have sex with men-National HIV Behavioral Surveillance System, 21 US cities United States, 2008. MMWR Surveill Summ. 2011;60:1-34.

49. Zhao P, Tang W, Cheng H, et al. Uptake of providerinitiated HIV and syphilis testing among heterosexual STD clinic patients in Guangdong, China: results from a cross-sectional study. BMJ Open. 2020;10: e041503.

50. Seth P, Wang G, Collins NT, et al. Identifying new positives and linkage to HIV medical care-23 testing site types, United States, 2013. Morb Mortal Wkly Rep. 2015;64:663-7.

51. Matulionytė R, Žagminas $\mathrm{K}$, Balčiūnaitè $\mathrm{E}$, et al. Routine HIV testing program in the University Infectious Diseases Centre in Lithuania: a four-year analysis. BMC Infect Dis. 2019;19:21.

52. Chen YJ, Lee CM, Chen M, Chuang SY, Liu HF, Wong WW, et al. Molecular epidemiology of HIV-1 infection in Taiwan from 2005 to 2008:further spread of CRF07_BC and emergence of CRFO7_ 
BC/subtype B dual infection. J Acquir Immune Defic Syndr. 2012;59:438-46.

53. Lin PH, Lai CC, Yang JL, et al. Slow immunological progression in HIV-1 CRF07_BC-infected injecting drug users. Emerg Microbes Infect. 2013;2: e83.

54. Yang CH, Huang YF, Hsiao CF, et al. Trends of mortality and causes of death among HIV-infected patients in Taiwan, 1984-2005. HIV Med. 2008;9: 535-43.

55. Yang CH, Yang SY, Shen MH, Kuo HS. The changing epidemiology of prevalent diagnosed HIV infections in Taiwan, 1984-2005. Int J Drug Policy. 2008;19:317-23.

56. Yazdanpanah Y, Perelman J, DiLorenzo MA, et al. Routine HIV screening in Portugal: clinical impact and cost-effectiveness. PLoS ONE. 2013;8: e84173.

57. Lenjiso GA, Endale BS, Bacha YD. Clinical and immunological failure among HIV-positive adults taking first-line antiretroviral therapy in Dire Dawa, eastern Ethiopia. BMC Public Health. 2019;19:771.

58. Long LC, Maskew M, Brennan AT, et al. Initiating antiretroviral therapy for HIV at a patient's first clinic visit: a cost-effectiveness analysis of the rapid initiation of treatment randomized controlled trial. AIDS. 2017;31:1611-9.

59. Lilian RR, Rees K, McIntyre JA, et al. Same-day antiretroviral therapy initiation for HIV-infected adults in South Africa: analysis of routine data. PLoS ONE. 2020;15: e0227572.

60. Joseph Davey D, Kehoe K. Same-day antiretroviral therapy is associated with increased lossto followup in South African public health facilities: a prospective cohort study of patients diagnosed with HIV. J Int AIDS Soc. 2020;23: e25529.

61. Lin T, Chen CH, Chou P. Effects of combination approach on harm reduction programs: the Taiwan experience. Harm Reduct J. 2016;13:23.

62. Daud MY, Qazi RA, Bashir N. Anti-retroviral drugs compliance in intravenous and non intravenous drug abusers. J Ayub Med Coll Abbottabad. 2014;26:437-40.

63. Ali B, Nisar N, Nawab F. Adherence to antiretroviral therapy in HIV-positive, male intravenous drug users in Pakistan. East Mediterr Health J. 2018;24: 237-42.

64. Rebeiro PF, Abraham AG, Horberg MA, et al. Sex, race, and HIV risk disparities in discontinuity of
HIV care After antiretroviral therapy initiation in the United States and Canada. AIDS Patient Care STDs. 2017;31:129-44.

65. Bitew BD, Berehane Y, Getahun E, Abyu D. Determinants of none-adherence to antiretroviral therapy among HIV-infected adults in Arba Minch General Hospital, Gamo Gofa Zone, Southern Ethiopia:a case control study. Am J Health Res. 2014;2:234-40.

66. Wasti SP, Simkhada P, Randall J, et al. Factors influencing adherence to antiretroviral treatment in Nepal: a mixed-methods study. PLoS ONE. 2012; 7: e35547.

67. Ferro EG, Culbert GJ, Wickersham JA, et al. Physician decisions to defer antiretroviral therapy in key populations: implications for reducing human immunodeficiency virus incidence and mortality in Malaysia. Open Forum Infect Dis. 2017;4:219.

68. Joseph B, Wood E, Hayashi K, et al. Factors associated with initiation of antiretroviral therapy among HIV-positive people who use injection drugs in a Canadian setting. AIDS. 2016;30:925-32.

69. Camoni L, Raimondo M, Regine V, et al. Late presenters among persons with a new HIV diagnosis in Italy, 2010-2011. BMC Public Health. 2013;13:281.

70. Barry A, Ford N, El-Khatib Z. Factors for incomplete adherence to antiretroviral therapy including drug refill and clinic visits among older adults living with human immunodeficiency virus - cross-sectional study in South Africa. Trop Med Int Health. 2018;23:270-8.

71. Ward EG, Disch WB, Schensul JJ, Levy JA. Understanding low-income, minority older adult selfperceptions of HIV risk. J Assoc Nurs AIDS Care. 2011;22:26-37.

72. Chiao EY, Ries KM, Sande MA. AIDS and the elderly. Clin Infect Dis. 1999;28(4):740-5.

73. Illa L, Brickman A, Saint-Jean G, et al. Sexual risk behaviors in late middle age and older HIV seropositive adults. AIDS Behav. 2008;12:935-42.

\section{Publisher's Note}

Springer Nature remains neutral with regard to jurisdictional claims in published maps and institutional affiliations. 